\title{
Hubungan Pengetahuan dan Sikap Keluarga dengan Terkendalinya Kadar Gula Darah pada Pasien Diabetes Melitus Tipe 2 (Studi di Rumah Sakit Umum Daerah Kabupaten Kediri)
}

\author{
Nanang Muhibuddin, ${ }^{1}$ Sugiarto, ${ }^{2}$ Hari Wujoso, ${ }^{3}$ \\ ${ }^{1}$ Prodi Magister Kedokteran Keluarga Program Pascasarjana, Universitas Sebelas Maret, \\ ${ }^{2}$ Subbagian Metabolik Endokrinilogi Bagian Ilmu Penyakit Dalam, \\ Fakultas Kedokteran Universitas Sebelas Maret / RSUD Dr. Moewardi Surakarta, \\ ${ }^{3}$ Bagian Ilmu Kedokteran Forensik dan Meikolegal, \\ Fakultas Kedokteran Universitas Sebelas Maret / RSUD Dr. Moewardi Surakarta
}

\begin{abstract}
Abstrak
Penyakit Diabetes Melitus jumlahnya terus meningkat serta menjadi masalah kesehatan karena komplikasinya, terjadi akibat kurangnya pengetahuan maupun sikap Keluarga dalam kontrol gula darah. Tujuan penelitian ini adalah untuk menganalisis hubungan pengetahuan dan sikap keluarga dengan terkendalinya kadar gula darah pada pasien DM tipe-2. Rancangan penelitian analitik dengan pendekatan cross sectional. Sampel 46 Responden keluarga (extended) pasien diambil dengan accidental sampling. Dilaksanakan di RSUD Kabupaten Kediri Bulan Februari sampai Maret 2016. Variabel bebas pengetahuan skor 0-30 dan sikap skor 0-120 tentang terkendalinya kadar gula darah dengan lembar kuesioner, variabel terikat Terkendalinya kadar gula darah Glycohemoglobin (HbAlc) dalam \% dengan lembar observasi Rekam Medis (HbA1c). Data dinyatakan dalam skala interval dan di analisis menggunakan Regresi Linier berganda. Tingkat kesalahan $(\alpha) 5 \%(0,05)$. Hubungan pengetahuan keluarga dengan terkendalinya kadar gula darah $(b=-0.29$; CI 95\% $=-0.53 \mathrm{~s} / \mathrm{d}-0.05 ; \mathrm{p}=0.017(30,1 \%))$. Hubungan sikap keluarga dengan terkendalinya kadar gula darah $(b=-0.125 ; \mathrm{CI} 95 \%=-0.22 \mathrm{~s} / \mathrm{d}-0.03 ; \mathrm{p}=0,012(31,1 \%))$. Hubungan pengetahuan dan sikap keluarga dengan terkendalinya kadar gula darah $p=0,001(37 \%)$ terkendalinya kadar gula darah pada pasien Diabetes Melitus tipe-2 dipengaruhi oleh faktor pengetahuan dan sikap. Ada hubungan pengetahuan dan sikap keluarga dengan terkendalinya kadar gula darah pada pasien diabetes mellitus tipe-2.
\end{abstract}

Kata kunci: Pengetahuan Keluarga, Sikap Keluarga, Terkendalinya kadar gula darah

\section{Correlation of Family Knowledge and Attitude with the Control of Blood Sugar Level in Patient with Type 2 Diabetes Mellitus (Study in RSUD District Kediri)}

\begin{abstract}
The amount of diabetes mellitus disease is increasing as well as become a health problem because of its complications, it is due to lack of knowledge, as well as family attitude, in the control of blood sugar. The objective of this research was to analyze the correlation of knowledge and family attitudes towards the control of blood sugar levels in patients with type-2 diabetes mellitus. The research design was observational analytic with approach of cross sectional. Sample amounted to 46 respondents of family patients (extended family) were taken by technique of accidental sampling. it conducted in RSUD Kabupaten Kediri from February to March 2016. The independent variables was knowledge score 0-30 and attitude score 0-120 about the control of blood sugar levels, independent variable was blood sugar levels of Glycohemoglobin (HbAlc) in \%. Technique of data collection used questionnaire sheet of knowledge and attitudes and observation sheet of Medical Record for HbAlc. Data are presented in scale of interval and analyzed using Linear regression. The error rate ( $\alpha$ ) 5\% (0.05). Correlation of family knowledge and control of blood sugar level $(b=-0.29 ; C I 95 \%=-0.53 \mathrm{~s} / \mathrm{d}-0.05 ; p=0.017(30,1 \%))$, Correlation of family attitude and control of blood sugar level $(b=-0.125 ; C I 95 \%=-0.22 \mathrm{~s} / d-0.03 ; p=0,012(31,1 \%)$. Correlation of knowledge and family attitude with control of blood sugar level $p=0,001$ (37\%) The control of blood sugar level in patient with Diabetis mellitus type-2 influenced by factors of knowledge and attitude. There is correlation of knowledge and family attitudes towards the control of blood sugar levels in patients with type-2 diabetes mellitus
\end{abstract}

Keywords: Family attitude, family knowledge, the control of blood sugar levels

Korespondensi:

Nanang Muhibuddin, dr

Prodi Magister Kedokteran Keluarga Program Pascasarjana, Universitas Sebelas Maret

Jl. Husni Thamrin Rt/Rw 002/004 Dusun Tawang Desa Sumberbendo Kec. Pare Kediri

Mobile : 08123122235

Email : nanang_dr80@yahoo.co.id 


\section{Pendahuluan}

Penyakit Diabetes Melitus (DM) sangat berpengaruh terhadap kualitas sumber daya manusia dan berdampak pada peningkatan biaya kesehatan yang cukup besar serta menjadi salah satu ancaman kesehatan global ${ }^{1,2}$. Terbukti bahwa penyakit ini jumlahnya dari tahun ke tahun terus meningkat tajam serta menjadi masalah kesehatan masyarakat utama karena komplikasinya bersifat jangka pendek dan panjang ${ }^{3}$. Berbagai penelitian epidemiologi menunjukkan ada kecenderungan peningkatan insidensi dan prevalensi DM tipe 2. Estimasi terakhir oleh International Diabetes Federation (IDF) terdapat 382 juta penderita DM di dunia pada tahun $2013^{4}$. WHO memprediksi kenaikan penderita DM di Indonesia dari 8,4 juta tahun 2000 menjadi 21,3 juta tahun $2030^{2}$.

Tingginya prevalensi DM tersebut karena perubahan gaya hidup, ketersediaan makanan tinggi kalori dan ketidakaktifan fisik menyebabkan obesitas dan diabetes ${ }^{3}$. Penyakit DM jika tidak dikelola dengan baik akan dapat mengakibatkan terjadinya berbagai penyulit menahun, seperti penyakit serebrovaskular, penyakit jantung koroner, penyakit pembuluh darah tungkai, gangguan pada mata, ginjal dan syaraf $^{2}$. Penyakit DM tipe 2 berkaitan dengan pengelolaan DM yang kurang baik seperti kurangnya pengendalian glukosa melalui diet/ gaya hidup sehat, latihan jasmani maupun obat/insulin ${ }^{2}$. Faktor yang mempengaruhi rendahnya kontrol gula darah pada DM tipe 2 yang menggunakan insulin yaitu gaya hidup, psikososial emosional, faktor yang berhubungan dengan pengobatan dan pengetahuan yang kurang 5 . Penelitian lain menyimpulkan bahwa pengetahuan tentang perawatan kaki dengan benar dapat menunda terjadinya bisul dan amputasi, membuat perubahan dalam perilaku yang salah dan mempromosikan kerjasama pasien dalam pengobatan dan selanjutnya perawatan diri ${ }^{6}$. UU Kesehatan No 36 tahun 2009 pasal 9 menyebutkan setiap orang berkewajiban ikut mewujudkan, mempertahankan, dan meningkatkan derajat kesehatan masyarakat yang setinggitingginya. Kewajiban sebagaimana dimaksud pelaksanaannya meliputi upaya kesehatan perseorangan, upaya kesehatan masyarakat, dan pembangunan berwawasan kesehatan. Keluarga perlu memberikan informasi guna meningkatkan pengetahuan pasien tentang pengendalian penyakitnya. Menggunakan pendekatan berpusat pada pasien dengan mengidentifikasi banyak hambatan untuk kontrol gula darah seperti ketidaktahuan dokter dari pasien bahwa mereka ketakutan, keyakinan, harapan dan keterbatasan pendekatan biomedis ke pasien yang kurang patuh $^{7}$. Anggota keluarga sangat berperan serta dalam pemberian intervensi pada pasien DM tipe 2 dalam memberikan dukungan emosional dan psikologis, membantu mengembangkan pengetahuan, sikap dan perilaku penderita yang sehat, serta mempromosikan manajemen diabetes secara mandiri ${ }^{8}$. American Diabetes Association (ADA) mengatakan bahwa perencanaan pengelolaan diabetes harus dibicarakan sebagai terapetik individual antara pasien dan keluarganya, dan pasien harus menerima perawatan medis secara terkoordinasi dan integrasi dari tim kesehatan, sehingga keluarga menyadari pentingnya keikutsertaan dalam perawatan penderita DM agar kadar gula darah penderita dapat terkendali dengan baik ${ }^{3}$.

Tujuan penelitian ini untuk mengetahui hubuungan pengetahuan dan sikap keluarga dengan terkendalinya kadar gula darah pada pasien Diabetes Melitus tipe 2. Pengetahuan merupakan hasil tahu, dan terjadi setelah orang melakukan penginderaan terhadap obyek tertentu. Penginderaan terjadi melalui panca indera manusia, yakni indera penglihatan, pendengaran, penciuman, rasa dan raba ${ }^{9}$. Faktor yang memengaruhi pengetahuan adalah pendidikan, pekerjaan, umur, minat, pengalaman, kebudayaan dan informasi. Pengukuran Pengetahuan dapat dilakukan dengan wawancara atau kuesioner yang menanyakan tentang isi materi yang ingin diukur dari subjek penelitian atau responden. Kedalaman pengetahuan yang ingin kita ketahui atau kita ukur dapat kita sesuaikan dengan tingkatan-tingkatan pengetahuan? ${ }^{9}$.

Sikap belum merupakan suatu tindakan atau aktivitas akan tetapi sikap merupakan predisposisi tindakan suatu perilaku9 9 . Pendidikan diabetes peka budaya pada biomedis, pengetahuan, sikap dan tindakan praktek berbasis kelompok dalam meningkatkan hasil biomedis dan perilaku pada pasien diabetes ${ }^{10}$. Gejala diabetes antara lain: rasa haus yang berlebihan (polidipsi), sering kencing (poliuri) terutama malam hari, sering merasa lapar (poliphagi), berat badan yang turun dengan cepat, keluhan lemah, kesemutan pada tangan dan kaki, gatal-gatal, penglihatan jadi kabur, impotensi, luka sulit sembuh, keputihan, penyakit kulit akibat jamur di bawah lipatan kulit, dan pada ibu-ibu sering melahirkan bayi besar dengan berat badan $\geq 4 \mathrm{~kg}^{1}$.

Ada 2 tipe Diabetes Melitus yaitu diabetes tipe 1 (diabetes juvenile) yaitu diabetes yang umumnya didapat sejak masa kanak-kanak dan diabetes tipe 2 yaitu diabetes yang didapat setelah dewasa ${ }^{4}$. Diagnosis DM ditegakkan atas dasar pemeriksaan kadar glukosa darah $\mathrm{HbA} 1 \mathrm{c}$ karena sangat konsisten dalam mendiagnosis diabetes ${ }^{11}$. Program kesehatan masyarakat akan 
diabetes Community health awareness of diabetes (CHAD) untuk mengidentifikasi individu yang berisiko tinggi untuk skrining diabetes berikutnya oleh dokter keluarga mereka ${ }^{12}$.

Pengendalian atau penatalaksanaan DM dimulai dengan menerapkan pola hidup sehat (terapi nutrisi medis dan aktivitas fisik) bersamaan dengan intervensi farmakologis dengan obat anti hiperglikemia secara oral dan/atau suntikan. Pada keadaan emergensi segera dirujuk ke pelayanan kesehatan sekunder atau tersier. Secara teknis pengendalian dilaksanakan melalui edukasi, Terapi Nutrisi Medis (TNM), latihan jasmani, terapi farmakologis ${ }^{2}$.

\section{Metode}

Rancangan penelitian adalah penelitian analitik dengan pendekatan cross sectional. Penelitian dilaksanakan di RSUD Kabupaten Kediri pada Bulan Februari sampai Maret 2016 yang sebelumnya sudah mendapatkan persetujuan dari Komisi Etik Penelitian Kesehatan RSUD Dr. Moewardi Fakultas Kedokteran UNS dengan no. 92/II/HREC/2016.

Populasi penelitian ini semua anggota keluarga yang mengantar yang dapat baca tulis dan pasien DM Tipe 2 di RSUD Kabupaten Kediri sebanyak
52 pasien selama 2 bulan dengan sampel 46 responden. Pengambilan sampel dengan tehnik accidental sampling dengan kriteria inklusi dapat baca tulis dan mengantar serta eksklusi yang menolak penelitian. Variabel bebas pengetahuan dan sikap keluarga dengan lembar kuesioner tentang terkendalinya kadar gula darah, variabel terikat kadar gula darah (HbA1c) dengan lembar observasi rekam medis untuk kadar gula darah HbA1c. Data dinyatakan dalam skala interval dan di analisis menggunakan Regresi Linier berganda.

\section{Hasil}

Data khusus penelitian; Data khusus penelitian yang merupakan variabel Pengetahuan Keluarga, Sikap Keluarga dan Terkendalinya kadar gula darah (HbA1c) dapat dilihat pada tabel 1.

Analisis Bivariat; Hubungan Pengetahuan Keluarga dengan Terkendalinya Kadar Gula Darah. Hasil Analisis Hubungan pengetahuan keluarga dengan terkendalinya kadar gula darah pada pasien diabetes mellitus tipe 2 dapat disajikan dalam diagram scater dibawah ini

Berdasarkan Diagram 1 diketahui ada kecenderungan hubungan pengetahuan keluarga dengan terkendalinya kadar gula darah pada

Tabel 1 Hasil Analisis Univariat Pengetahuan Keluarga, Sikap Keluarga dan Terkendalinya kadar gula darah (HbA1c) di RSUD Kab. Kediri

\begin{tabular}{lccc}
\hline \multicolumn{1}{c}{ Variabel } & Mean & Std. Dev & \% \\
\hline Pengetahuan Keluarga & 22,22 & 2,8 & 74,1 \\
Sikap Keluarga & 74,11 & 6,8 & 61,8 \\
HbA1c & 8,07 & 2,3 & 73.4 \\
\hline
\end{tabular}

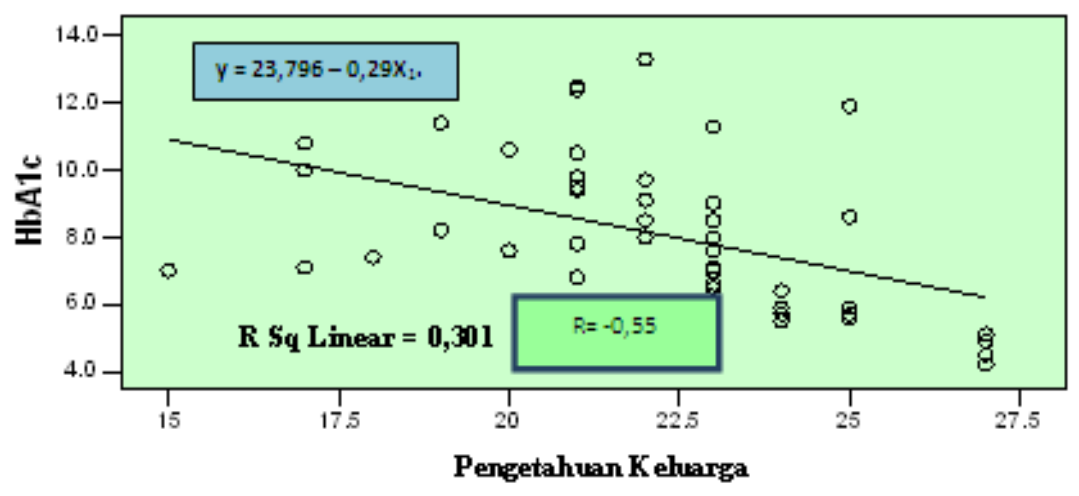

Diagram 1 Hubungan Pengetahuan Keluarga dengan Terkendalinya Kadar Gula Darah pada Pasien Diabetes Melitus Tipe 2 di Rumah Sakit Umum Daerah Kabupaten Kediri 


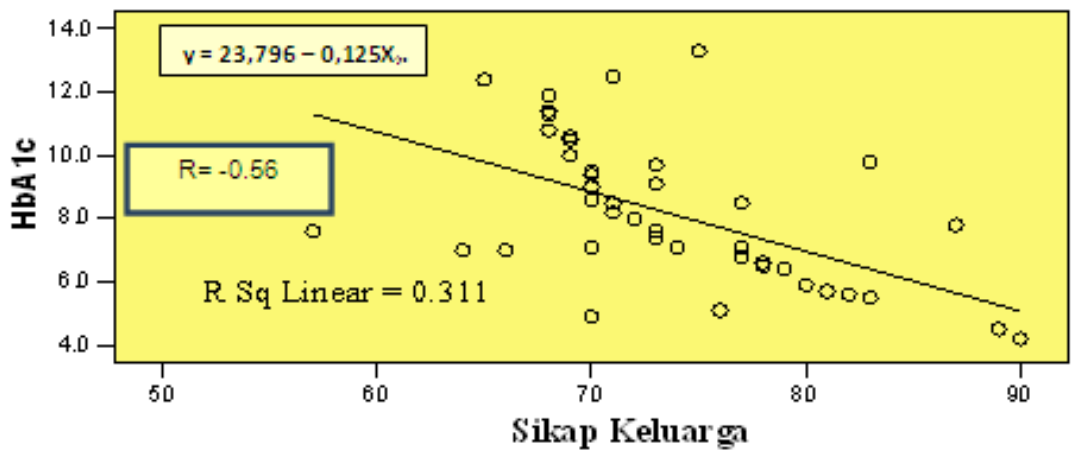

Diagram 2 Hubungan Sikap Keluarga dengan Terkendalinya Kadar Gula Darah pada Pasien Diabetes Mellitus Tipe 2 di Rumah Sakit Umum Daerah Kabupaten Kediri

Tabel 2 Hasil Analisis Regresi Linier Hubungan Pengetahuan dan Sikap Keluarga dengan Terkendalinya Kadar Gula Darah pada Pasien Diabetes Mellitus Tipe 2

\begin{tabular}{lccc}
\hline \multicolumn{1}{c}{ Variabel } & Koefisien Regresi (b) & T & p \\
\hline Konstanta & 23,80 & 7,78 & 0,001 \\
Pengetahuan & $-0,29$ & $-2,49$ & 0,017 \\
Sikap & $-0,13$ & $-2,63$ & 0,012 \\
n observasi $=46$ & & & \\
Adjusted $R^{2}=37 \%$ & & & \\
$\mathrm{p}<0,05$ & & & \\
\hline
\end{tabular}

pasien diabetes melitus tipe 2 yaitu dengan semakin tinggi skor pengetahuan maka hasil $\mathrm{HbA} 1 \mathrm{c}$ semakin rendah. Koefisien determinasi $\mathrm{r}$ Sq Linear $\left(\mathrm{R}^{2}\right)$ 0,301 artinya 30,1\% terkendalinya kadar gula darah (HbA1c) dipengaruhi oleh pengetahuan keluarga, sedangkan sisanya 69,9\% karena faktor lain yang tidak dapat dijelaskan dalam persamaan regresi tersebut. Konstanta pengetahuan adalah -0,29 (bernilai negatif) artinya tanpa ada penambahan skor pengetahuan keluarga maka dapat memberikan kemungkinan penurunan kadar HbA1c sebesar -0,29 kali atau dalam persamaan $\mathrm{y}=23,796-0,29 \mathrm{X}_{1}$.

Pengaruh Sikap Keluarga dengan Terkendalinya Kadar Gula Darah. Hasil analisis pengaruh sikap keluarga terhadap terkendalinya kadar gula darah pada pasien diabetes mellitus tipe 2 dapat disajikan dalam diagram scater. Berdasarkan Diagram 2 diketahui ada kecenderungan hubungan sikap keluarga dengan terkendalinya kadar gula darah pada pasien diabetes mellitus tipe 2 yaitu dengan semakin tinggi skor sikap maka hasil HbAlc semakin rendah. Koefisien determinasi $\mathrm{r}$ Sq Linear $\left(\mathrm{R}^{2}\right)$ 0,311 artinya $31,1 \%$ terkendalinya kadar gula darah (HbA1c) dipengaruhi oleh sikap, sedangkan sisanya $68.9 \%$ karena faktor lain yang tidak dapat dijelaskan dalam persamaan regresi tersebut. Konstanta sikap adalah $-0,13$ (bernilai negatif) artinya tanpa ada penambahan skor sikap maka memberikan kemungkinan penurunan kadar HbA1c sebesar $-0,13$ kali atau dalam persamaan $\mathrm{y}=23,796-0,13 \mathrm{X}_{2}$

Analisis Multivariat; Hubungan Pengetahuan dan Sikap Keluarga dengan Terkendalinya Kadar Gula Darah. Berdasarkan Tabel 2 di atas diketahui hubungan pengetahuan dan sikap keluarga dengan terkendalinya kadar gula darah pada pasien diabetes mellitus tipe 2 di RSUD Kabupaten Kediri $(\mathrm{p}=0,001<0,05)$, dengan persamaan $\mathrm{y}=23,80-0,29 \mathrm{X} \neg 1-0,13 \mathrm{X} \neg 2$. Koefisien determinasi (R2) $37 \%$ artinya $37 \%$ terkendalinya kadar gula darah pada pasien diabetes mellitus tipe 2 dipengaruhi oleh faktor pengetahuan dan sikap, sedangkan sisanya $63 \%$ karena faktor lain yang tidak dapat dijelaskan dalam persamaan regresi tersebut. Konstanta pengetahuan adalah $-0,29$ (bernilai negatif) artinya semakin tinggi skor pengetahuan maka semakin rendah kadar HbA1c dan tanpa adanya 
peningkatan skor pengetahuan (skor 0) maka akan memberikan kemungkinan penurunan kadar HbA1c sebesar -0,29 kali. Konstanta untuk sikap adalah $-0,13$ (bernilai negatif) artinya semakin tinggi skor sikap maka semakin turun kadar $\mathrm{HbA} 1 \mathrm{c}$ dan tanpa adanya peningkatan skor sikap maka akan memberikan kemungkinan penurunan kadar HbA1c sebesar -0,13 kali (pengetahuan b $=-0.29 ;$ CI $95 \%=-0.53 \mathrm{~s} / \mathrm{d}-0.05 ; \mathrm{p}=0.017$; sikap $\mathrm{b}=-0.125$; CI $95 \%=-0.22 \mathrm{~s} / \mathrm{d}-0.03, \mathrm{p}=$ $0.012)$.

\section{Pembahasan}

Hubungan Pengetahuan Keluarga dengan Terkendalinya Kadar Gula Darah pada Pasien Diabetes Mellitus Tipe 2; Berdasarkan Diagram 1 analisis bivariat diketahui ada Kecenderungan pengaruh pengetahuan keluarga terhadap terkendalinya kadar gula darah pada pasien diabetes mellitus tipe 2 yaitu semakin tinggi skor pengetahuan maka hasil HbA1c semakin rendah. Koefisien determinasi $\mathrm{r}$ Sq Linear (R2) 0,301 artinya $30,1 \%$ terkendalinya kadar gula darah ( $\mathrm{HbA} \mathrm{cc}$ ) dipengaruhi oleh pengetahuan keluarga, sedangkan sisanya $69,9 \%$ karena faktor lain yang tidak dapat dijelaskan dalam persamaan regresi tersebut. Konstanta pengetahuan adalah -0,29 (bernilai negatif) artinya tanpa ada penambahan skor pengetahuan maka memberikan kemungkinan penurunan kadar $\mathrm{HbAlc}$ sebesar 0,29 kali atau dalam persamaan $\mathrm{y}=23,796-$ $0,29 X 1$. Pada tabel 2 analisis multivariat nilai $\mathrm{p}=0.017$, hal ini berarti bahwa ada pengaruh yang signifikan antara pengetahuan keluarga terhadap terkendalinya kadar gula darah pada pasien DM tipe 2. Meningkatkan pengetahuan tentang diabetes dan aset psikososial keluarga bermanfaat untuk mempromosikan perilaku kesehatan keluarga yang positif otomatis juga pasien $\mathrm{DM}^{13}$. Melibatkan anak-anak dan orang tua selaku anggota keluarga dalam managemen diabetes meningkatkan pengetahuan dan perilaku yang dapat bermanfaat dalam mengelola pasien $\mathrm{DM}^{14}$. Sebaiknya keluarga mempunyai pengetahuan tentang apa saja faktor risiko yang dapat memengaruhi kadar gula darah bisa naik (hiperglikemia) atau turun (hipoglikemia) diantaranya yaitu cara pengendalian stres, infeksi, kaki diabetes, gangguan ginjal, diabetes dengan kehamilan, diabetes dengan ibadah puasa, diabetes yang menggunakan steroid, gangguan ginjal $^{2}$. Rendahnya kontrol gula darah pada DM tipe 2 yang menggunakan insulin yaitu gaya hidup, psikososial emosional, faktor yang berhubungan dengan pengobatan dan pengetahuan yang kurang. 5 . Intervensi pendidikan pada keluarga dapat memberikan dukungan emosional dan psikologis membantu mempromosikan perilaku yang sehat ${ }^{8}$.

Meningkatkan pengetahuan keluarga otomatis meningkatkan pengetahuan pasien DM, karena itu agar berhasil pengelolaan pengendalian kadar gula darah pasien DM tipe 2 maka melibatkan anggota keluarga dalam setiap kontrol rutin di pelayanan kesehatan mutlak diperlukan mengingat sebagian pasien DM tipe 2 adalah orang lanjut usia yang sudah mengalami sebagian kemunduran organ fisiologisnya seperti penglihatan, pendengaran dan memori. Pengetahuan lain yang harus ditingkatkan baik pasien maupun keluarga adalah seperti pengendalian penyebabnya, yang meliputi pengendalian kenaikan berat badan bisa mengarah kepada timbulnya obesitas, pengendalian timbulnya komplikasi penyakit lain, serta perencanaan diit dan olah raga yang sesuai dengan pedoman untuk penderita DM.

Hubungan Sikap Keluarga dengan Terkendalinya Kadar Gula Darah pada Pasien Diabetes Mellitus Tipe 2; Berdasarkan Diagram 2 analisis bivariat diketahui ada kecenderungan pengaruh sikap keluarga terhadap terkendalinya kadar gula darah pada pasien diabetes mellitus tipe 2 yaitu dengan semakin tinggi skor sikap maka hasil HbAlc semakin rendah. Koefisien determinasi $\mathrm{r}$ Sq Linear $\left(\mathrm{R}^{2}\right)$ 0,311 artinya $31,1 \%$ terkendalinya kadar gula darah $(\mathrm{HbAlc})$ dipengaruhi oleh sikap, sedangkan sisanya $68.9 \%$ karena faktor lain yang tidak dapat dijelaskan dalam persamaan regresi tersebut. Konstanta sikap adalah $-0,13$ (bernilai negatif) artinya tanpa ada penambahan skor sikap maka memberikan kemungkinan penurunan kadar $\mathrm{HbA1c}$ sebesar $-0,13$ kali atau dalam persamaan $\mathrm{y}=23,796-$ $0,13 \mathrm{X}_{2}$. Sedangkan tabel 2 analisis multivariat nilai $\mathrm{p}=0.012$, hal ini berarti bahwa ada pengaruh yang signifikan antara sikap keluarga terhadap terkendalinya kadar gula darah pada pasien DM tipe 2

Sikap juga didefinisikan sebagai respon tertutup dari seseorang terhadap stimulus atau objek tertentu yang melibatkan faktor pendapat dan emosi (senang-tidak senang, setuju-tidak setuju, baik-tidak baik, dan sebagainya) ${ }^{9}$. Sikap terhadap kesehatan mulut dan diabetes mellitus para peserta dalam kelompok intervensi lebih tinggi dibandingkan kelompok kontrol untuk berolahraga, mengubah diet, memiliki pemeriksaan kaki, selalu memakai sepatu tertutup, berpartisipasi dalam skrining diri kaki, menggunakan benang gigi, dan menggunakan sikat gigi antar-proksimal ${ }^{15}$. Tinggal bersama dengan pasien DM memiliki manfaat tak terduga dalam menurunkan profil risiko penyakit karena perilaku kesehatan yang lebih baik dan hubungan 
yang lebih dekat dengan sistem perawatan kesehatan $^{16}$.

Pada penelitian ini memperlihatkan tidak hanya pengetahuan saja yang perlu dimiliki oleh keluarga namun juga aplikasi dari pengetahuan yaitu sikap yang mereka miliki, misalnya mereka tahu bahwa penderita Diabetes Melitus perlu mengendalikan pola makanannya, untuk itu mereka juga mau mengontrol makanan yang dimakan oleh penderita Diabetes, mengajak kontrol rutin ke sarana kesehatan, berolahraga sesuai jadwal dan minum obat rutin serta menghilangkan stres. Sehingga kemungkinan kadar gula darah meninggi dapat terminimalisir dengan baik dan komplikasi terhindarkan.

Hubungan Pengetahuan dan Sikap Keluarga dengan Terkendalinya Kadar Gula Darah Pada Pasien Diabetes Mellitus Tipe 2; Berdasarkan tabel 2 analisis multivariat diketahui Adjusted $R^{2}=37 \%$ itu berarti secara keseluruhan variabel pengetahuan dan sikap keluarga memberi pengaruh terhadap terkendalinya $\mathrm{HbA1c}$ sebesar $37 \%$. Konstanta pengetahuan dan sikap adalah 23,796 (bernilai positif) artinya tanpa ada penambahan skor pengetahuan dan sikap maka memberikan kemungkinan penurunan kadar HbA1c sebesar 23,796 kali atau dalam persamaan $y=23,796-0,29 X_{1}-0,13 X_{2}$. nilai $p=0,001$, hal ini berarti bahwa ada pengaruh yang signifikan antara pengetahuan dan sikap keluarga terhadap terkendalinya kadar gula darah pada pasien DM tipe 2 (pengetahuan $\mathrm{b}=-0.29 ;$ CI 95\% $=-0.53$ $\mathrm{s} / \mathrm{d}-0.05 ; \mathrm{p}=0.017$; sikap $\mathrm{b}=-0.125$; CI $95 \%=$ $-0.22 \mathrm{~s} / \mathrm{d}-0.03, \mathrm{p}=0.012)$. Intervensi pendidikan untuk mengurangi kesenjangan kesehatan dengan mengembangkan budaya perawatan diabetes tertentu harus fokus pada keterlibatan keluarga dengan pendidikan lanjutan ${ }^{17}$. Memberikan pendidikan diabetes dan pelatihan keterampilan perawatan diri untuk meningkatkan pengetahuan, sikap dan perawatan diri ${ }^{1}$. Merupakan strategiyang efektif untuk meningkatkan kontrol metabolik dan mengurangi komplikasi dan tingkat kematian DM tipe $2^{18}$. Pendidikan diabetes pengelolaan diri pada manajemen glukosa dan pemberdayaan etnis meningkatkan keterampilan manajemen diabetes perawatan diri ${ }^{19}$. Mengembangkan ketrampilan, membangun kepercayaan diri dan mengubah perilaku kesehatan yang positif ${ }^{20}$. Pada penelitian ini tidak hanya pengetahuan saja yang perlu dimiliki oleh keluarga namun juga aplikasi dari pengetahuan yaitu sikap yang mereka miliki, misalnya mereka tahu bahwa penderita Diabetes Melitus perlu mengendalikan pola makanannya, untuk itu mereka juga mau mengontrol makanan yang dimakan si penderita Diabetes, mengajak kontrol rutin ke sarana kesehatan, berolahraga sesuai jadwal dan minum obat rutin serta menghilangkan stres, juga diperlukan motivasi dan perilaku pasien yang baik Sehingga kemungkinan kadar glukosa meninggi dapat terminimalisir dengan baik dan komplikasi terhindarkan kualitas hidup pasien terjaga baik serta mencegah DM baru pada anggota tersebut.

Adapun keterbatasan dan kelemahan yang ada antara lain; Tidak semua faktor yang memengaruhi terkendalinya kadar gula darah diteliti. Faktor yang perlu diteliti lebih lanjut antara lain adalah motivasi, perilaku, budaya dan faktor geografis. Penelitian ini menggunakan desain cross sectional (potong lintang). Pada desain cross sectional semua variabel diukur pada saat yang sama sehingga tidak dapat memastikan besar hubungan antara pengetahuan dan sikap keluarga sebagai sebab serta terkendalinya kadar gula darah sebagai akibat. Dengan demikian pada penelitian selanjutnya perlu dipertimbangkan desain penelitian yang lebih baik yaitu menggunakan Desain Cohort, Ada hubungan pengetahuan keluarga dengan terkendalinya kadar gula darah pada pasien diabetes mellitus tipe 2, Penambahan skor pengetahuan maka memberikan kemungkinan penurunan kadar HbA1c, Ada hubungan sikap keluarga dengan terkendalinya kadar gula darah pada pasien diabetes mellitus tipe 2. Penambahan skor sikap maka memberikan kemungkinan penurunan kadar HbA1c, Ada hubungan pengetahuan dan sikap keluarga dengan terkendalinya kadar gula darah pada pasien diabetes mellitus tipe 2. Penambahan skor pengetahuan dan sikap maka memberikan kemungkinan penurunan kadar $\mathrm{HbAlc}$, Sebaiknya anggota keluarga meluangkan waktu untuk menambah pengetahuan pengendalian DM secara menyeluruh sehingga mempunyai sikap yang baik dalam merawat sehingga pasien DM akan termotivasi dan berperilaku positif dalam perawatan diri yang pada tujuannya gula darah dapat terkedali, komplikasi terhindarkan kualitas hidup menjadi baik seperti orang normal, Untuk memperkuat hasil penelitian ini, diperlukan penelitian di masa yang akan datang dengan memperhatikan variabel pengganggu terhadap hasil HbA1c pasien DM tipe 2 dengan mempertimbangkan rumah tangga untuk intervensi menargetkan pencegahan primer dan sekunder, Sebaiknya dalam memberikan edukasi memperhatikan latar belakang Pasien dan keluarga serta strategi yang efektif sehingga dapat mendukung keberhasilan pengendalian kadar HbAlc pada pasien DM tipe 2 dan mencegah DM pada keluarganya, Berdasar hasil penelitian dan telaah kepustakaan, penulis menyarankan pihak pendidikan untuk menjadikan bahan pengabdian masyarakat tentang pelatihan keterampilan penatalaksanaan DM secara menyeluruh. 


\section{Daftar Pustaka}

1. Zareban I, Karimy M, Niknami S, Haidamia A, Rakhshani F. The effect of self-care education program on reducing $\mathrm{HbA} 1 \mathrm{c}$ levels in patients with type 2 diabetes. J Educ Health Promot; 2014 Nov 29;3:123.

2. PB. Perkeni. Konsensus Pengelolaan dan Pencegahan Diabetes Mellitus Tipe 2 di Indonesia. Jakarta : Perkeni; 2015.

3. Bilous, R \& Donelly, R. Buku Pegangan Diabetes, Edisi ke 4, Cetakan 1, Jakarta: Bumi Medika; 2015.

4. Pusat Data Dan Informasi Sekretariat Jenderal Kementrian Kesehatan Indonesia Data dan Informasi Tahun 2014 (Profil Kesehatan Indonesia). Kementrian Kesehatan RI; 2014.

5. Tong WT, Vethakkan SR, Ng CJ. Why do Some People with Type 2 Diabetes Who are Using Insulin Have Poor Glycemic Control? A Qualitative Study. BMJ Open. 2015 Jan 29;5(1):e006407.

6. Natalia De Sa P, Moura JR, De Melo Junior EB, De Almeida PC, De Macedo SF, Da silva AR. Knowledge, Attitudes And Practices for The Prevention of Diabetic Foot. . Rev Gaucha Enferm. 2014 Sep;35(3):36-42.

7. Janes R, Tichener J, Pere J, Pere R, Senior J. Understanding Barriers to Glyceamic Control from The Patient's Perspective. J Prim Health Care. 2013 Jun 1;5(2):114-22.

8. $\mathrm{Hu}$ J, Wallace D, McCoy T, Amirehsani K. A Family-Based Diabetes Intervention for Hispanic Aduls and Treir Family Members. Diabetes Educ. 2014 Jan-Feb;40(1):48-59.

9. Notoatmodjo. S. Ilmu Perilaku kesehatan, Jakarta: PT RINEKA CIPTA; 2010.

10. Muhammed H, Al-Leniawi B, Amuna P, Zotor F, Elmahdi H. Culturally Sensitive Patient Centred Education Programme for Self-Management of Type 2 Diabetes : a Randomized Controlled Trial. Prim Care Diabetes. 2013 Oct; 7(3) : 199-206.

11. Guan X, Zheng L, Sun G, Guo X, Li Y, Song $\mathrm{H}$, dkk. The changing relationship between HbAlc and FPG according to different FPG ranges.J Endocrinol Invest. 2015 Sep 18.

12. Agarwal G, Kaczorowski J, Hanna S. Community health awareness of diabetes (CHAD): description of a community-wide diabetes awareness demonstration program and its feasibility. Can J Diabetes. 2013 Oct;37(5):294-300.

13. Gefter L, Rosas LG, Rodriguesz E, MoriokaDauglas N. Training at-risk youth to become diabetes self-management coaches for family members: partnering family medicine residents with underserved schools. Diabetes Educ. 2014 Nov-Dec;40(6):786-96.

14. Sullivan BS, Bova C, Johnson K, Cullen K, Jaffarian C, Quinn D, dkk. Engaging teens and parents in collaborative practice: perspectives on diabetes self-management. Diabetes Educ. 2014 Mar-Apr;40(2):178-90.

15. Saengtipbovorn S \& Taneepanichskul S. Lifestyle Change Plus Dental Care (LCDC) Program Improves Knoledge, Attitude, and Practice (KAP) toward Oral Health and Diabetes Mellitus Among The Elderly With Type 2 Diabetes. J Med Assoc Thai. 2015 Mar; 98(3): 279-90.

16. Nielsen J, Bahendeka SK, Gregg EW, Whyte SR, Bygbierg IC, Mevrowitsch DW. 2015 A Comparison of Cardiometabolic Risk Factors in Households in Rural Uganda With and Without a Resident With Type 2 Diabetes, 2012 - 2013. Prev Chronic Dis. 2015 Apr 2;12:E44.

17. Newman S, Cheng T, Ghahate DM, Bobelu J, Sandy P, Faber T, dkk. Assessing knowledge and attitudes of diabetes in Zuni Indians using a culture-centered approach. . PLoS One. 2014 Jun 11;9(6):e99614.

18. Yuan C, Lai CW, Chan LW, Chow M, Law HK, Ying M. The effect of diabetes selfmanagement education on body weight, glycemic control, and other metabolic markers in patients with type 2 diabetes mellitus. J Diabetes Res. 2014;2014:789761.

19. Naccashian Z. The impact of diabetes self-management education on glucose management and empowerment in ethnic Armenians with type 2 diabetes. Diabetes Educ. 2014 Sep-Oct;40(5):638-47.

20. Dasgupta K, Jarvandi S, Civita MD, Pillay S, Hajna S, Gougeon R, dkk. Participant's Perceptions of Group Based Program Incorating Hands - On Meal Preparation and Pedometer - Based Self- Monitoring in Type 2 Diabetes. PLoS One. 2014 Dec 23; 9(12): e114620. 